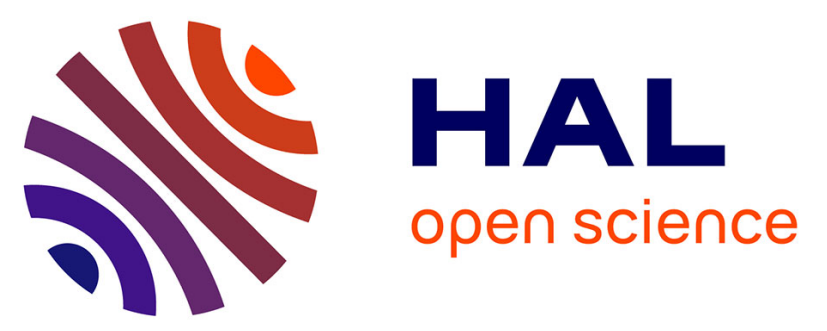

\title{
Investigation of New Approaches for InGaN Growth with High Indium Content for CPV Application
}

\author{
Muhammad Arif, Suresh Sundaram, Jérémy Streque, Youssef El Gmili,
} Renaud Puybaret, Sofiane Belahsene, Abderahim Ramdane, Anthony Martinez, Gilles Patriarche, Thomas Fix, et al.

\section{To cite this version:}

Muhammad Arif, Suresh Sundaram, Jérémy Streque, Youssef El Gmili, Renaud Puybaret, et al.. Investigation of New Approaches for InGaN Growth with High Indium Content for CPV Application. CPV 11, Apr 2015, Aix-Les-Bains, France. pp.040001, 10.1063/1.4931512 . hal-01212599

\section{HAL Id: hal-01212599 \\ https://hal.science/hal-01212599}

Submitted on 19 Jan 2022

HAL is a multi-disciplinary open access archive for the deposit and dissemination of scientific research documents, whether they are published or not. The documents may come from teaching and research institutions in France or abroad, or from public or private research centers.
L'archive ouverte pluridisciplinaire HAL, est destinée au dépôt et à la diffusion de documents scientifiques de niveau recherche, publiés ou non, émanant des établissements d'enseignement et de recherche français ou étrangers, des laboratoires publics ou privés.

\section{(ㅇ)(1) $\$$}

Distributed under a Creative Commons Attribution - NonCommerciall 4.0 International 


\title{
Investigation of New Approaches for InGaN Growth with High Indium Content for CPV Application
}

\author{
Muhammad Arif ${ }^{1,2}$, Suresh Sundaram ${ }^{1}$, Jérémy Streque $^{1}$, Youssef El Gmili ${ }^{1}$, \\ Renaud Puybaret ${ }^{3}$, Sofiane Belahsene ${ }^{4}$, Abderahim Ramdane ${ }^{4}$, Anthony Martinez ${ }^{4}$, \\ Gilles Patriarche ${ }^{4}$, Thomas Fix ${ }^{5}$, Abdelillah Slaoui ${ }^{5}$, Paul L. Voss ${ }^{3}$, Jean Paul \\ Salvestrini $^{1,2, a)}$, and Abdallah Ougazzaden ${ }^{1,3}$ \\ ${ }^{1}$ CNRS, UMI 2958 Georgia Tech - CNRS, 57070 Metz, France \\ ${ }^{2}$ Université de Lorraine \& CentraleSupelec, LMOPS, EA4423, 57070 Metz, France \\ ${ }^{3}$ Georgia Institute of Technology, UMI 2958 Georgia Tech - CNRS, 57070 Metz, France \\ ${ }^{4}$ CNRS, UPR LPN, Route de Nozay, 91460 Marcoussis, France \\ ${ }^{5}$ CNRS, ICUBE - Université de Strasbourg, France \\ ${ }^{a)}$ Corresponding author: salvestr@metz.supelec.fr
}

\begin{abstract}
We propose to use two new approaches that may overcome the issues of phase separation and high dislocation density in InGaN-based PIN solar cells. The first approach consists in the growth of a thick multi-layered InGaN/GaN absorber. The periodical insertion of the thin GaN interlayers should absorb the In excess and relieve compressive strain. The InGaN layers need to be thin enough to remain fully strained and without phase separation. The second approach consists in the growth of InGaN nano-structures for the achievement of high In content thick InGaN layers. It allows the elimination of the preexisting dislocations in the underlying template. It also allows strain relaxation of InGaN layers without any dislocations, leading to higher In incorporation and reduced piezo-electric effect. The two approaches lead to structural, morphological, and luminescence properties that are significantly improved when compared to those of thick InGaN layers. Corresponding full PIN structures have been realized by growing a p-type GaN layer on the top the half PIN structures. External quantum efficiency, electro-luminescence, and photo-current characterizations have been carried out on the different structures and reveal an enhancement of the performances of the InGaN PIN PV cells when the thick InGaN layer is replaced by either InGaN/GaN multi-layered or InGaN nanorod layer.
\end{abstract}

\section{INTRODUCTION}

Thanks to their band gap spanning almost the whole solar spectrum from $0.7 \mathrm{eV}$ (InN) to $3.4 \mathrm{eV}$ ( $\mathrm{GaN}$ ), InGaN alloys are considered as promising candidates for high-efficiency photovoltaic devices [1,2]. This makes the development of all-InGaN multijunction solar cells with an overall efficiency larger than $50 \%$ theoretically possible. For this, high-quality and thick InGaN layers with high In content are required. This is not an easy task. Reports of InGaN-based junctions with an In mole fraction exceeding 0.3 are rare [1] and the performance of InGaN-based photovoltaic cells, whatever the In content, still remain far from the theoretical ones [3-6]. Issues such as strong phase separation and relaxation of the layer due to lattice mismatch with the substrate, lead to InGaN layers with large dislocation density and In-clustering, even if absorbing layers in the form of a multiple quantum well [6] have been used to delay strain relaxation. In this paper, we propose to use two new approaches (see Fig.1) that may overcome the issues of phase separation and high dislocation density in the absorber and thus grow InGaN-based PIN solar cells with improved properties. The first approach consists to replace the conventional bulk absorber by a thick multi-layered InGaN/GaN absorber. The periodical insertion of the thin GaN interlayers should absorb the excess In and relieve compressive strain. These $\mathrm{GaN}$ interlayers need to be thick enough to be effective and thin enough to allow carrier transport through tunneling. The InGaN layers need to be thick and numerous enough to 
absorb efficiently the incoming light beam, and thin enough to remain fully strained and without phase separation. The second approach consists in the growth of InGaN nano-structures for the achievement of high In content thick InGaN layers. This approach allows the elimination of the preexisting dislocations in the underlying template [7]. It also allows strain relaxation of InGaN layers without any dislocations, leading to higher In incorporation [8] and reduced piezo-electric effect.
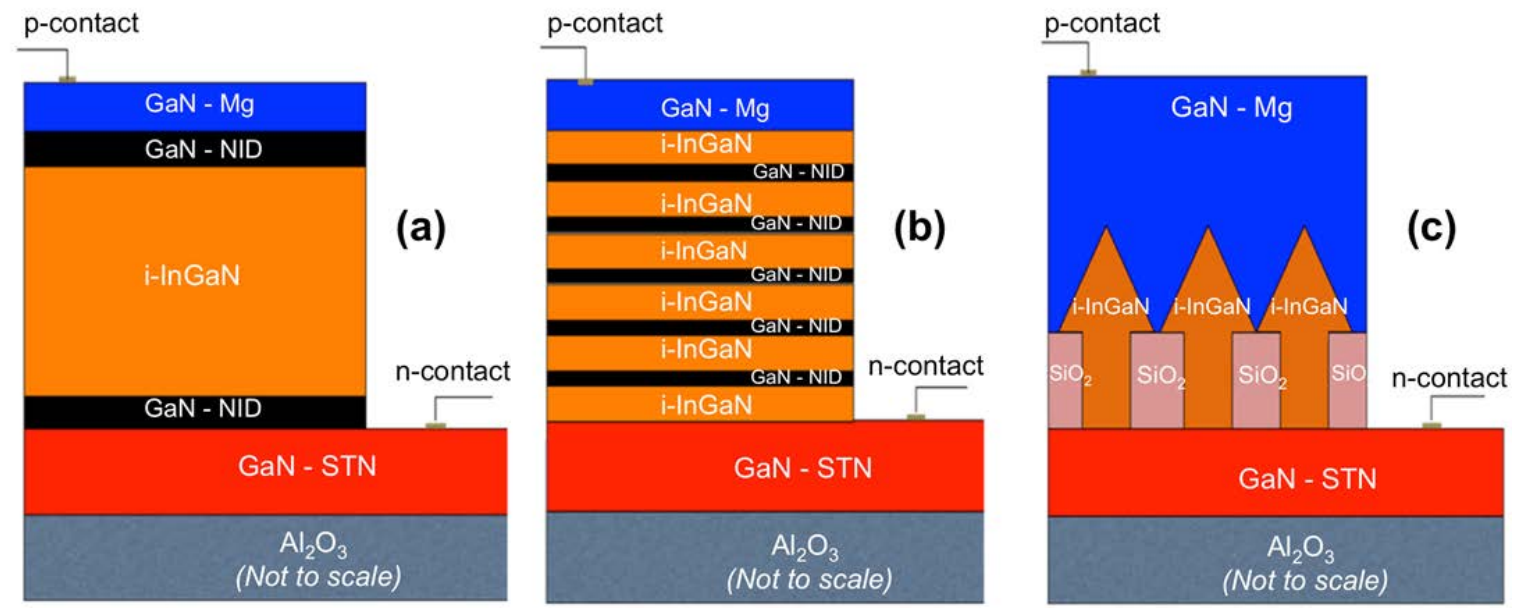

FIGURE 1. The two nanoscale approaches for the InGaN absorber growth of PIN structures: a) thick layer, b) multi-layered structure, c) nanorods structure

\section{EXPERIMENT}

Two sets of InGaN samples were grown at $800^{\circ} \mathrm{C}$ on GaN templates using a MOVPE reactor [9]. Nitrogen was used as the carrier gas and trimethylgallium (TMGa), trimethylindium (TMIn) and ammonia were employed as precursor sources for $\mathrm{Ga}$, In and elemental $\mathrm{N}$, respectively. The reactor pressure was 100 Torr and the V/III ratio equal to 8000. For the first set of samples, the ratio of TMIn to the sum of TMIn and TMGa in the vapor phase (TMIn/III) was kept constant at $45 \%$. A reference InGaN single-layer (C-sample) and a multilayered structure (Msample) were grown for comparison. The M-samples were grown by periodically stopping the In precursor flow into the reactor. The two targeted structures consist of $16 \times 1.5 \mathrm{~nm}$ thick GaN interlayers, inserted periodically between $17 \times 7 \mathrm{~nm}$ thick InGaN layers, respectively, resulting in a total structure thickness of $143 \mathrm{~nm}$. The InGaN and GaN periodicity and layer thicknesses are based on simulations and previous experimental results on the relaxation of InGaN layers [10]. For the second set of samples, nano-patterned substrates were fabricated on $\mathrm{n}$-doped $2 \mu \mathrm{m}$ thick c-oriented GaN/sapphire template following a procedure described in Ref. [8]. First, a $100 \mathrm{~nm}$ thick negative-tone resist (hydrogen silsesquioxane, HSQ) is spin-coated on the template. The resist is then patterned using an electronbeam lithography system providing a $4 \mathrm{~nm}$ Gaussian beam, that we used at $100 \mathrm{kV}$ accelerating voltage, under a 1.9 $\mathrm{nA}$ current. The part of the resist exposed to the electron beam cross-links into $\mathrm{SiO}_{2}$. At last, $\mathrm{TMAH} 25 \%$ etching treatment is used to open the nano-patterns (nano-holes and nano-stripes). The diameter of the circular opening is $100 \mathrm{~nm}$ and the size of the stripe openings is $10 \times 0.1 \mu \mathrm{m}^{2}$ with an orientation along the (110) direction. The structural properties of the InGaN layers and nanostructures were characterized using transmission electron microscopy (TEM). Their surface morphology has been observed by scanning electron microscopy (SEM) and atomic force microscopy (AFM). Optical emission properties of $\mathrm{InGaN}$ structures are investigated by cathodoluminescence (CL) technique. InGaN PIN structures based on both approaches were then grown and characterized for their external quantum efficiency, and, dark and illuminated I-V.

\section{RESULTS}

\section{InGaN absorber}

- Multilayered approach

Figure 2 shows HAADF-STEM images of (a) the C- and (b) M-sample which are described in Fig. 3. In the 
control sample one can clearly distinguish two sublayers, particularly the top, rough, three-dimensional sublayer. AFM measurements (not shown here) reveal that the RMS roughness of this layer is $14.3 \mathrm{~nm}$. This threedimensional sublayer has been suppressed in the M-sample, which is two-dimensional all the way to the top, with an RMS roughness of $3.1 \mathrm{~nm}$.
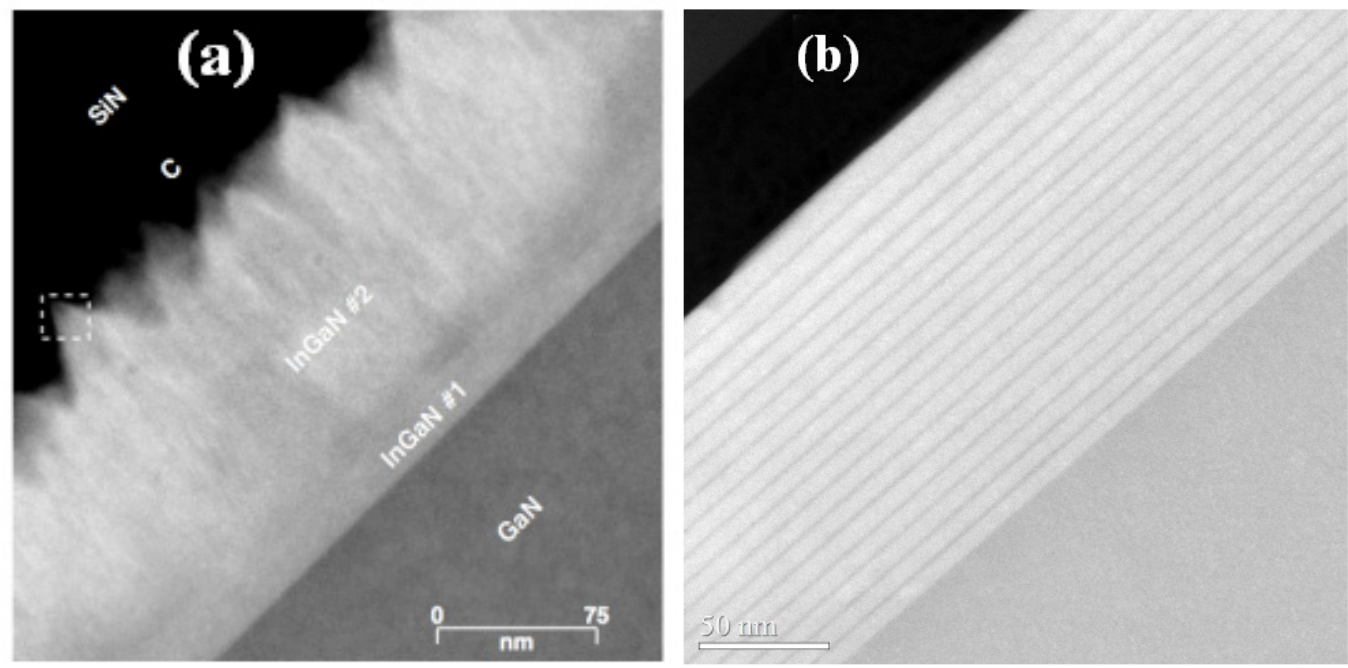

FIGURE 2. TEM images of a) C-sample, compared to b) M-sample

Figure 4a) shows typical large area room-temperature depth-resolved CL spectra measured in the C-sample for electron beam energy varying from 3 to $11 \mathrm{keV}$. A double peak structure, corresponding to the InGaN band-edge emission, is clearly shown irrespective of the beam energy. For clarity, the lower and higher peak wavelength positions are referred as InGaN\#1 and InGaN\#2 and correspond to values of $\lambda=410 \mathrm{~nm}$ and $\lambda=450 \mathrm{~nm}$ (at $5 \mathrm{keV}$ ), respectively. Since the region of maximum energy loss moves progressively from the near surface to the near interface region, and this point of maximum excitation produces a maximum of luminescence intensity, the related InGaN\#2 and InGaN\#1 CL emission peaks are attributed to the InGaN near-surface sublayer and the InGaN/GaN interface region, respectively. As shown in Fig. 4b), a large area CL study of the M-sample reveals at room temperature a single CL peak $(\lambda=400 \mathrm{~nm}$ at $7 \mathrm{keV})$. CL study of the C-sample (Fig. 4a)) shows that the InGaN layer is composed of two distinct sublayers with different strain-relaxation states and In contents instead of CL study of the M-sample (Fig. 4b)) which demonstrate the improvement of the InGaN layer quality when using the multilayered growth technique which reveals one luminescence peak corresponding to the existence of only one InGaN phase with $7.6 \% \pm 1 \%$ (CL data) In concentration.
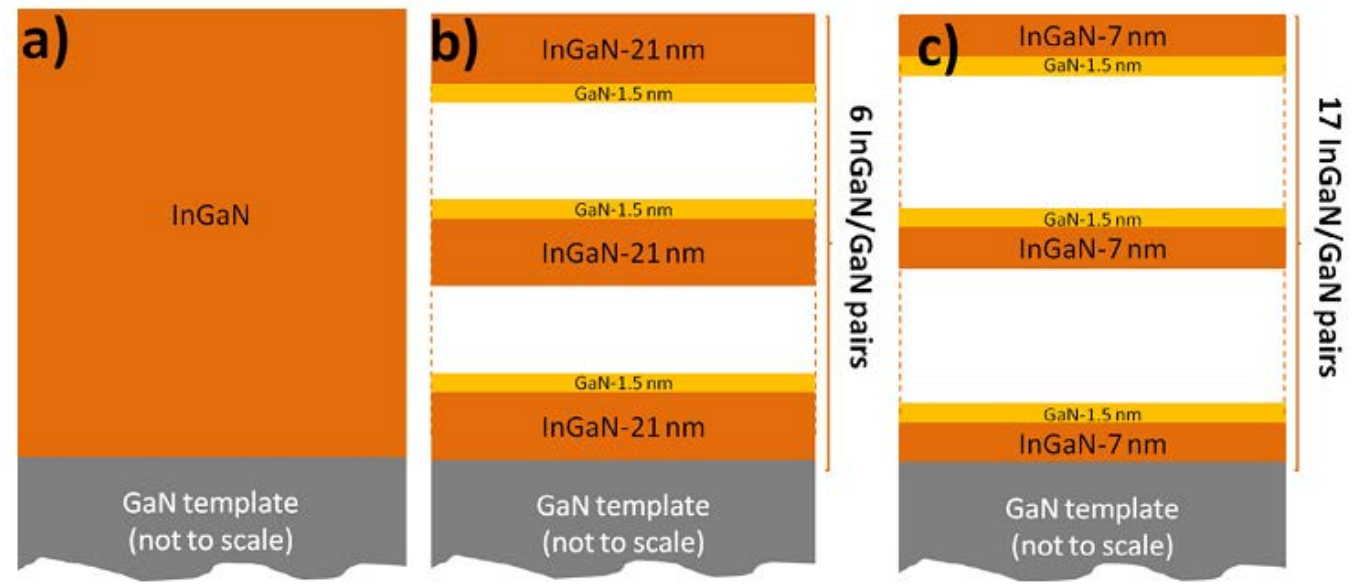

FIGURE 3. Schematic representation of: C-sample with $\mathrm{InGaN} 126 \mathrm{~nm}(\mathrm{In}=10.2 \%, 14.3 \%)$, M-sample with $\mathrm{InGaN} 120 \mathrm{~nm}$ $(\mathrm{In}=10.2 \%)$ (b), M-sample with $\mathrm{InGaN} 120 \mathrm{~nm}(\mathrm{In}=14.3 \%)$ (c) 

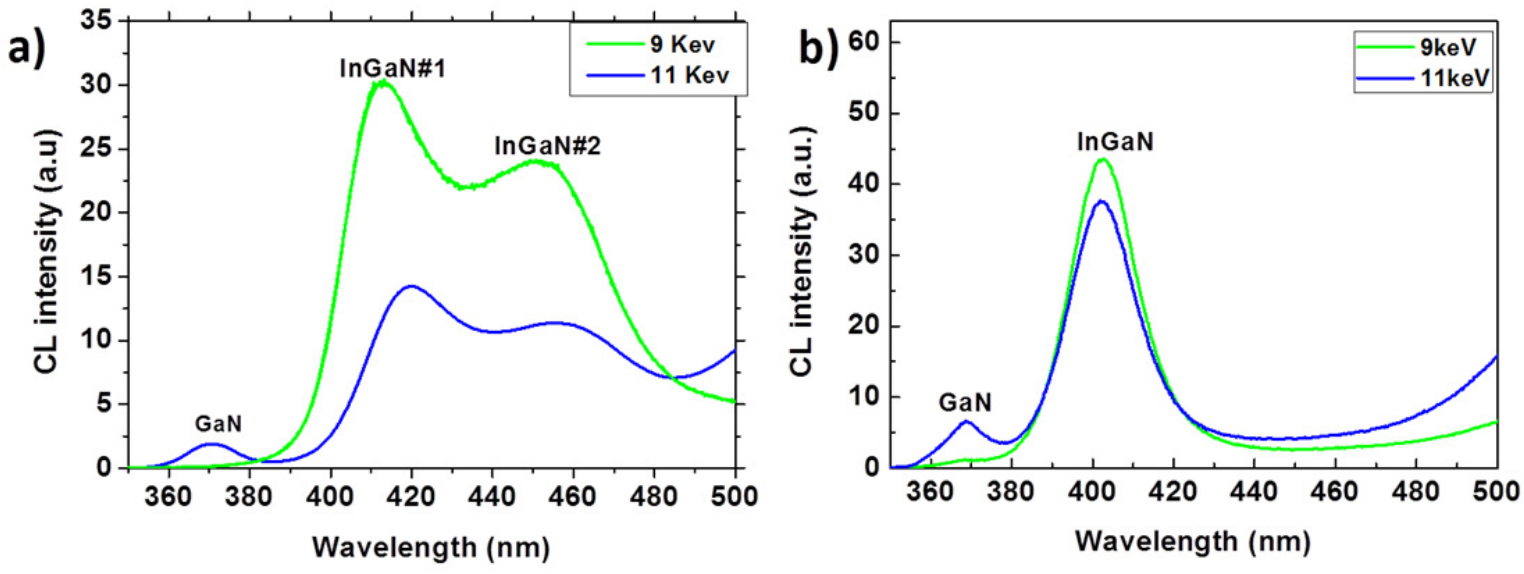

FIGURE 4. Room-temperature CL spectra of C-sample (a), M-sample (b)

To further investigate the M-layer approach for high In incorporation, two structures (see Fig.3) with 14.3\% of In incorporation are compared. The InGaN sublayer thickness for the M-sample was decreased based on the simulation results [10]. According to CL hyperspectral mapping done for both C- and M- samples [11], the spatial variations of the luminescence wavelength position for the $\mathrm{C}$ sample shows two different phases: one characterized by a luminescence peak wavelength centered at $\lambda \approx 435 \mathrm{~nm}$, and another one characterized by a luminescence peak wavelength centered at $\lambda \approx 490 \mathrm{~nm}$. In comparison the M-sample shows only one phase characterized by a luminescence peak wavelength centered at $\lambda \approx 433 \mathrm{~nm}$ with low inhomogeneity except some small variations).

- Nanorods approach

Figure 5a) and 5b) show SEM images of perfectly selective InGaN nanostructures grown on circular and stripe openings in the patterned substrate, respectively. As a result of optimized growth conditions, InGaN growth on the patterned area is perfectively selective, without any polycrystalline deposits on the masks. The pattern with circular openings contains InGaN nanorods with very good uniformity which has a hexagonal pyramid shape and has been grown without any defect. It is clear that InGaN nanostripes show an elongated hexagonal pyramid shape. InGaN nanostructures exhibit well defined shape and size uniformity, exposing the six (1-102) triangular r-plane facets with some irregular triangular r-plane facet formation on the two elongated sidewalls. Even though there is some inhomogeneity in the sidewall morphology of InGaN stripes, both nanostructures are smooth which means that a 3D stress relief mechanism is in place. This mechanism mitigates strain induced degradation, usually present in planar InGaN, which induces inclusions, V-pits, trench pits, In clustering, and 3D growth as shown by the SEM images in the unmasked area of the sample.
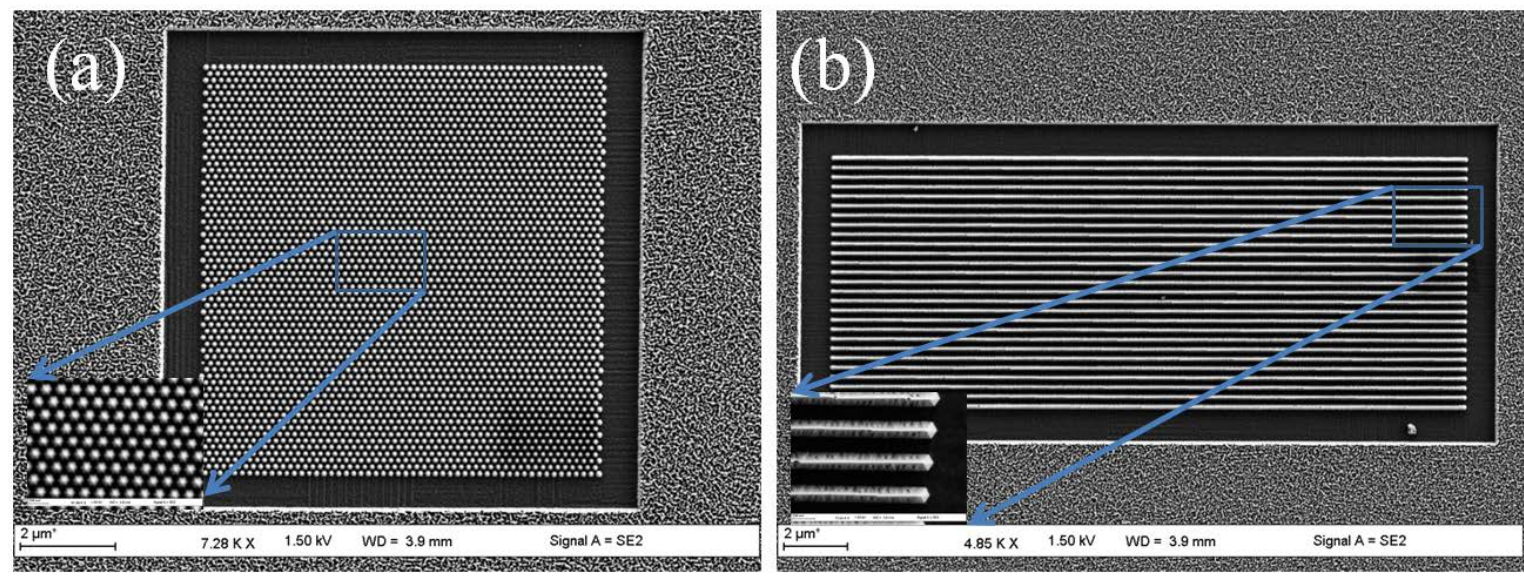

FIGURE 5. SEM images of perfectly selective thick InGaN nanostructure arrays grown on GaN templates in circular opening a) and stripe opening b). 
Figure 6a) and 6b) show HAADF STEM images of single InGaN nanorod and nanostripe, respectively. The hexagonal pyramid shaped nanorod has no threading dislocation as it can be seen in Fig. 6a). These results show clearly that the InGaN nanorod is single crystal with slightly misoriented grains, one being housed inside the $\mathrm{SiO}_{2}$ mask and the other emerging out from the mask with hexagonal pyramid shape. Fig. 6b) shows clear contrast difference between the GaN and InGaN layers, the latter having extra $\mathrm{r}$ plane triangular facets on the sidewalls when compared to InGaN nanorods. Along the c-axis of the InGaN layer, there are two regions with large contrast difference. The first region called InGaN1 has an In incorporation of around 13\% and the second one, called InGaN2, an In content around 20\% (both evaluated using localized EDX measurements not shown here). The InGaN1 sublayer starts to grow along the c-axis with semipolar r-plane facets and forms the core of the nanostripe. Then the InGaN2 sublayer grows on these semipolar r-plane surfaces. This figure also shows the boundary region with a slight misorientation between InGaN1 and InGaN2 sublayers. The growth on the semipolar facets is of importance and has advantages over the conventional c-axis growth since it allows reduction of the piezoelectric polarization effects which can play a detrimental role in the performance of solar cells based on InGaN material.
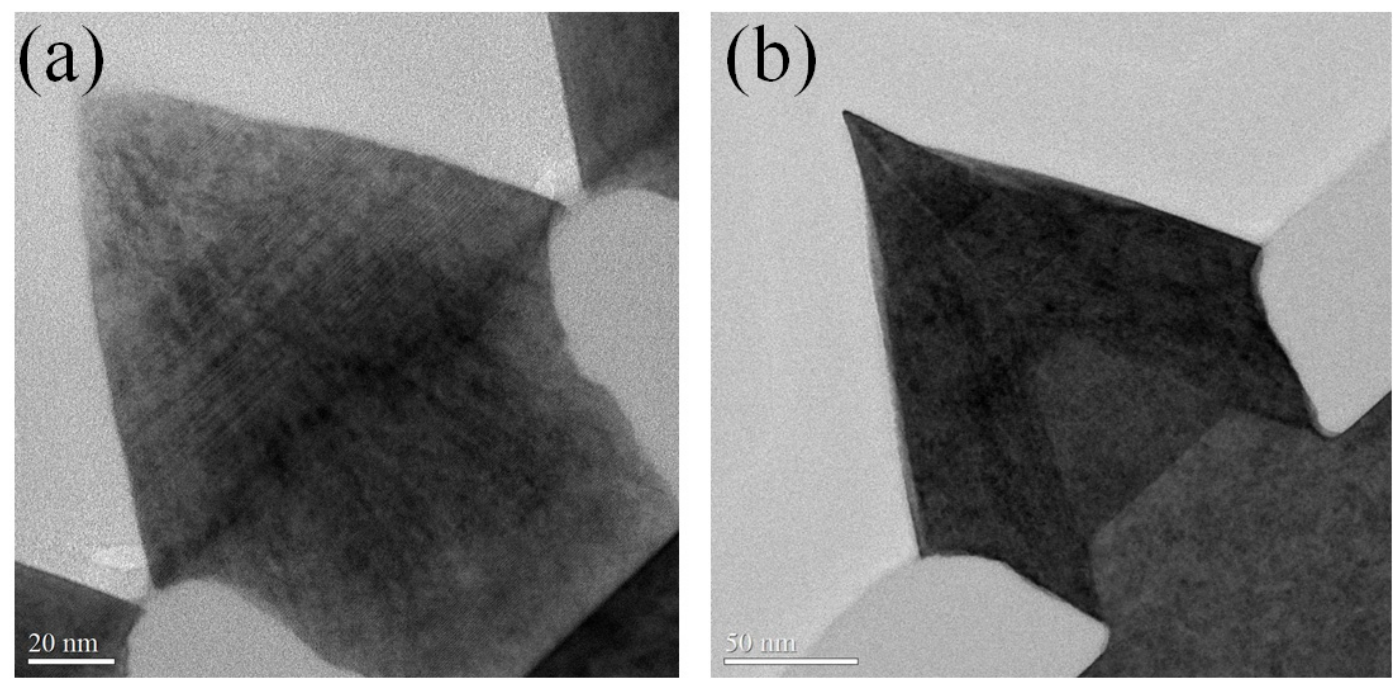

FIGURE 6. HAADF cross-sectional STEM images of InGaN nanorod a) and nanostripe b)

Figure 7 shows the low temperature $(77 \mathrm{~K}) \mathrm{CL}$ spectra at $5 \mathrm{keV}$ in planar InGaN, and single InGaN nanostripe and nanorod, respectively. This electron beam energy corresponds to a depth of maximum energy loss of $30 \mathrm{~nm}$, and thus, the spectra reveal mainly the luminescence of the InGaN layer. In contrast to the single luminescence peak centered around $535 \mathrm{~nm}$ obtained for the InGaN nanorod, both the InGaN nanostripe and planar InGaN exhibit two luminescence bands, centered at $464 \mathrm{~nm}$ and $525 \mathrm{~nm}$ for the nanostripe, and $420 \mathrm{~nm}$ and $520 \mathrm{~nm}$ for the planar InGaN. We can also notice a broad luminescence band centered around $590 \mathrm{~nm}$ which is attributed to the GaN defect band. In the planar InGaN, the presence of the two luminescence bands can be attributed to the presence of strained InGaN1 and relaxed InGaN2 sublayers [11,12] whereas the two luminescence bands observed in the nanostripe might be attributed to the fully relaxed InGaN1 and InGaN2 regions as shown in Fig. 7. According to the EDX measurement (not shown here), the In content of the strained and fully relaxed sublayers of planar InGaN are $12 \%$ and $21 \%$, respectively. In the nanostripe, the In composition of the two relaxed layers are $14 \%$ and $21 \%$, whereas in the nanorod only one relaxed InGaN phase with $22 \%$ of In is revealed. This is expected since, as shown in Fig. 7, unlike the nanostripe which exhibits a structure with a core (InGaN1) and sidewalls (InGaN2), the nanorod is single crystal (InGaN2) with growth directions along axes perpendicular to r-planes. For the same growth condition, the In incorporation in the nanorods is a little larger than in the nanostripes and almost twice as high as in planar InGaN. 


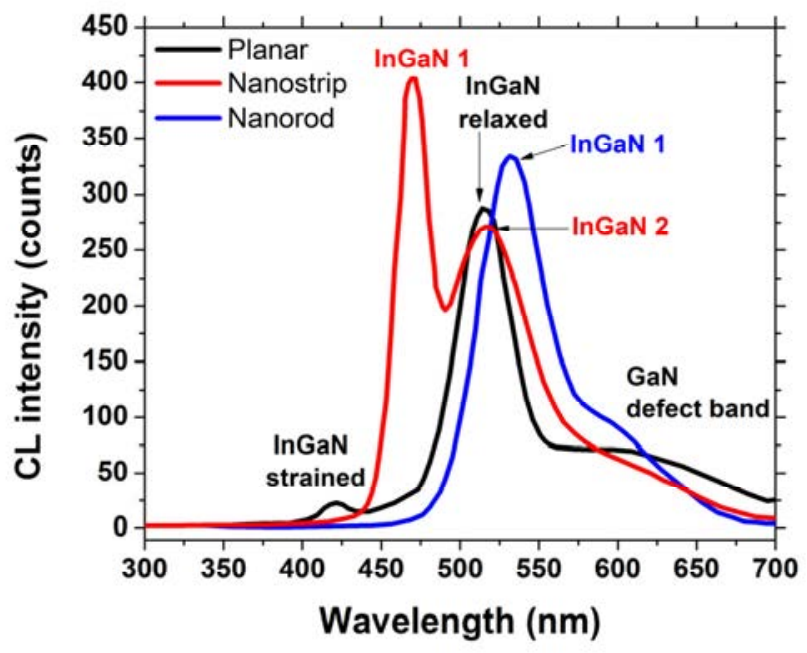

FIGURE 7. CL spectra of single InGaN nanostructures.

\section{Full PIN structure}

The next step was to build solar cells PIN structures using both the previous approaches for growing the InGaN absorber. Several challenges are involved, due to the complex nature of layers doped with various impurities i.e. player with $\mathrm{Mg}$ and n-layer with Si. The structure design used for the full p-i-n solar cell is shown in Fig. 8a). The realization of each technological brick is described below.

\section{- $\quad \mathrm{p}-\mathrm{GaN}$ and $\mathrm{n}-\mathrm{GaN}$ layers}

$\mathrm{GaN}$ has an $\mathrm{n}$-type nature due to the nitrogen and/or oxygen vacancies. Moreover, silicon is widely used for $\mathrm{n}$ type doping of $\mathrm{GaN}$. The n-type nature of $\mathrm{GaN}$ facilitates the goal of highly negative doped layer with $\mathrm{Si} . \mathrm{Mg}$ is the most commonly used as p-dopant. Though there exist few alternatives i.e. $\mathrm{Ca}, \mathrm{Zn}, \mathrm{Be}$ studied in the literature, they were never able to replace $\mathrm{Mg}$ doping. $\mathrm{Mg}$ with its deep nature in the band gap requires high activation energy. Considering the important role of a p-layer in constructing a quality solar cell, it's crucial to find efficient techniques of $\mathrm{Mg}$ activation. Various approaches like, annealing under different ambient at high temperatures are found to be useful but till now these techniques only made it possible to activate $1 \%$ of $\mathrm{Mg}$. The $99 \%$ of neutral $\mathrm{Mg}$ acceptors, up to a certain degree are responsible for the poor mobility. We used four different activation techniques that include activation under nitrogen and/or oxygen using RTA, in-situ annealing under nitrogen ambient and laser annealing. A detailed analysis of current transport mechanisms through different samples activated under different conditions showed that in-situ annealing was the optimized process for activating $\mathrm{Mg}$.

- Ohmic contacts

High resistance ohmic contacts to $\mathrm{p}-\mathrm{GaN}$ and $\mathrm{n}-\mathrm{GaN}$ can highly impact the collection of carriers and thus the efficiency of the solar cell relies on the quality of the metal contacts. Metal contacts to p-GaN and n-GaN with low resistance are as important as the absorption layer. Fabrication of low resistance ohmic contacts on $\mathrm{n}-\mathrm{GaN}$ has not been as difficult as on $\mathrm{p}-\mathrm{GaN}$. We used $\mathrm{KOH}$ and $\mathrm{HCl}: \mathrm{H}_{2} \mathrm{O}$ surface treatments for oxide removal prior lithography. The $\mathrm{HCl}: \mathrm{H} 2 \mathrm{O}$ treated sample showed a much lower value of specific contact resistivity than those treated with $\mathrm{KOH}$. The Ti/Al/Au metal contacts were annealed in RTA at $600^{\circ} \mathrm{C}$ for 80 seconds under oxygen. Using the CTLM technique, the values for specific contact resistance was calculated to be $1.8 \times 10^{-4} \Omega \mathrm{cm}^{2}$.

For ohmic contacts on $\mathrm{p}-\mathrm{GaN}$ we used $\mathrm{KOH}, \mathrm{HCl}$ and $\mathrm{HCl}: \mathrm{H}_{2} \mathrm{O}$ as wet chemical treatments prior to $\mathrm{Ni} / \mathrm{Au}$ metal deposition, with two different ambient conditions (nitrogen, oxygen) for annealing after metallization. Fig. 8 shows the I-V characteristic of Ni/Au metal contacts to p-GaN. Before annealing, the contacts are non-ohmic but after annealing in RTA under oxygen for 5 minutes, the contacts turn to be ohmic. Ni/Au metals contacts results in a specific contact resistivity of $2.8 \times 10^{-3} \Omega \mathrm{cm}^{2}$ after annealing under oxygen at $500^{\circ} \mathrm{C}$ for 5 minutes. 

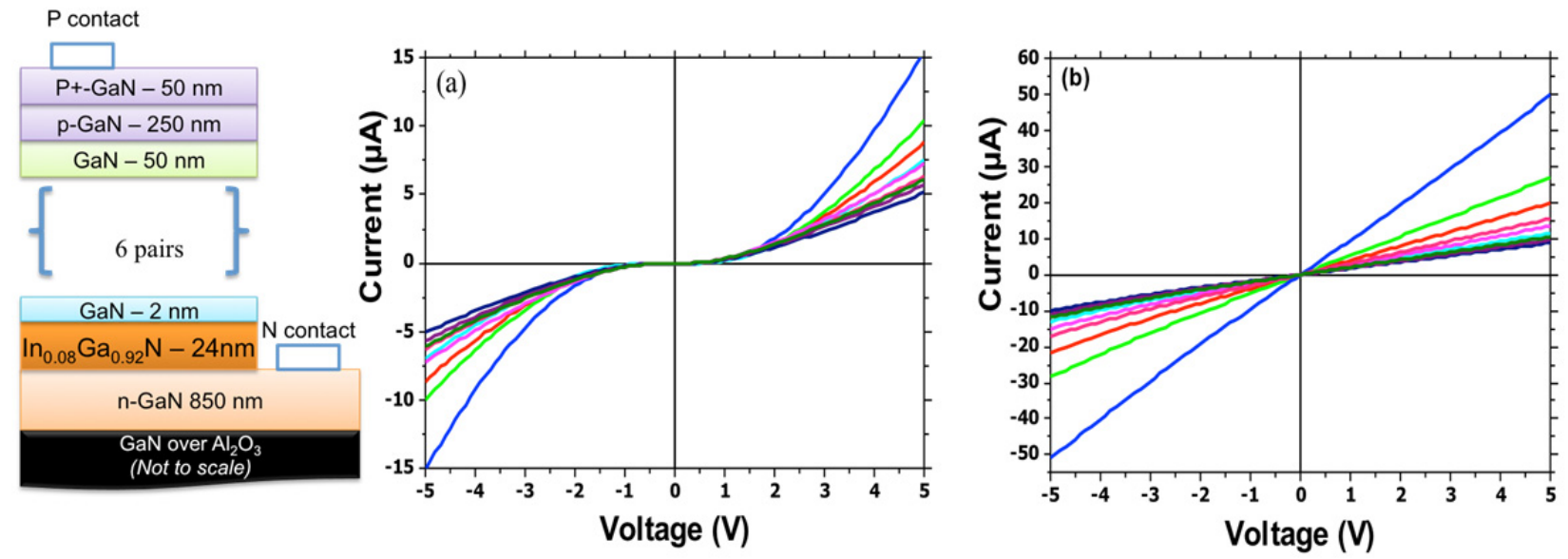

FIGURE 8. Ni/Au Ohmic contacts to $\mathrm{p}-\mathrm{GaN}$, before annealing (left), after annealing under oxygen (right)

- Multilayered approach based PIN structure

A multilayered structure is used for fabricating solar cells with various dimensions. Our target was to investigate multilayer approach with $8 \%$ of In incorporation. A total of 6 pairs with InGaN and GaN interlayer thicknesses of 24 $\mathrm{nm}$ and $2 \mathrm{~nm}$ respectively are used for the absorption layer, making its total thickness of $144 \mathrm{~nm}$ for the intrinsic region. A $50 \mathrm{~nm}$ GaN cap layer was then grown to secure the InGaN degradation during the growth of $200 \mathrm{~nm}$ thick $\mathrm{p}-\mathrm{GaN}$ at $1000{ }^{\circ} \mathrm{C}$. Finally a p+-GaN (heavily doped with $\mathrm{Mg}$ ) layer was grown with a thickness of $50 \mathrm{~nm}$. The final device is shown in Fig. 10 b) and c). A typical external quantum efficiency (EQE) measurement is shown in Fig. 9 d). The sharp decrease of the EQE at a cut-off wavelength of $400 \mathrm{~nm}$ suggests a high quality of the absorber. The low EQE below $365 \mathrm{~nm}$ is due to the photon absorption and charges generation in the p-GaN layer that cannot be collected in the depletion region [13]. A maximum peak of the EQE equal to $85 \%$ is observed at the wavelength of $378 \mathrm{~nm}$. To our knowledge, this is the maximum EQE peak reported so far in the literature for an InGaN absorber layer with $8 \%$ of indium incorporation. I-V characteristics measured under AM $1.5 \mathrm{G}\left(100 \mathrm{~mW} / \mathrm{cm}^{2}\right) \mathrm{conditions}^{2}$ shown in Fig. 10.

(a)

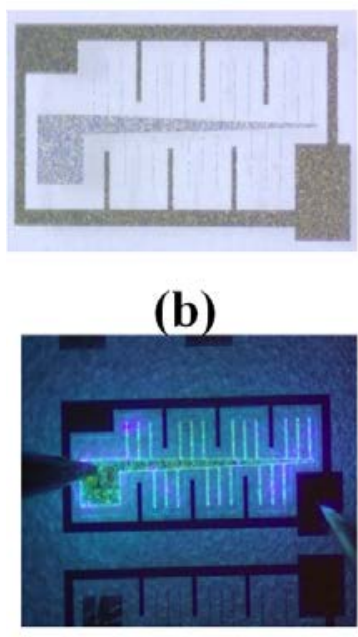

(c)

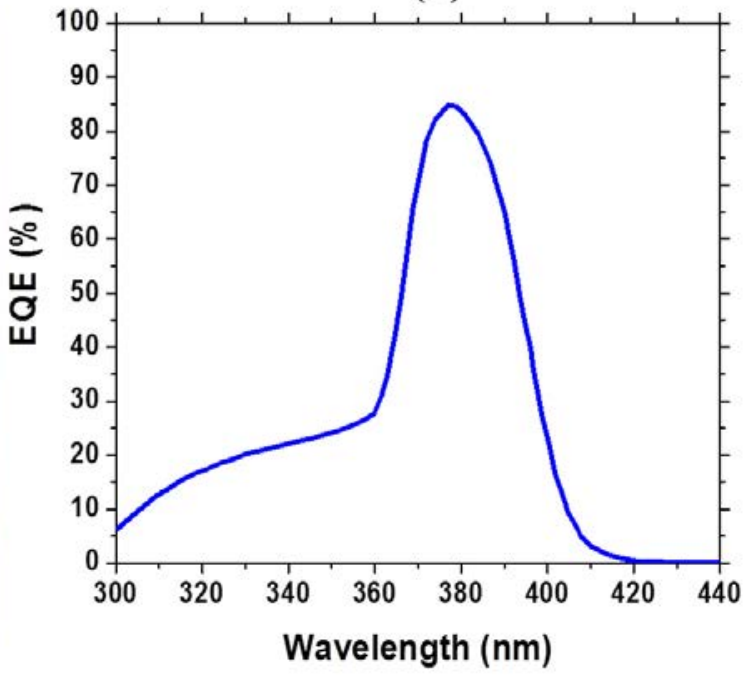

FIGURE 9. a) Fabricated PIN device, b) luminescence recorded under current injection, and c) corresponding EQE measurement 

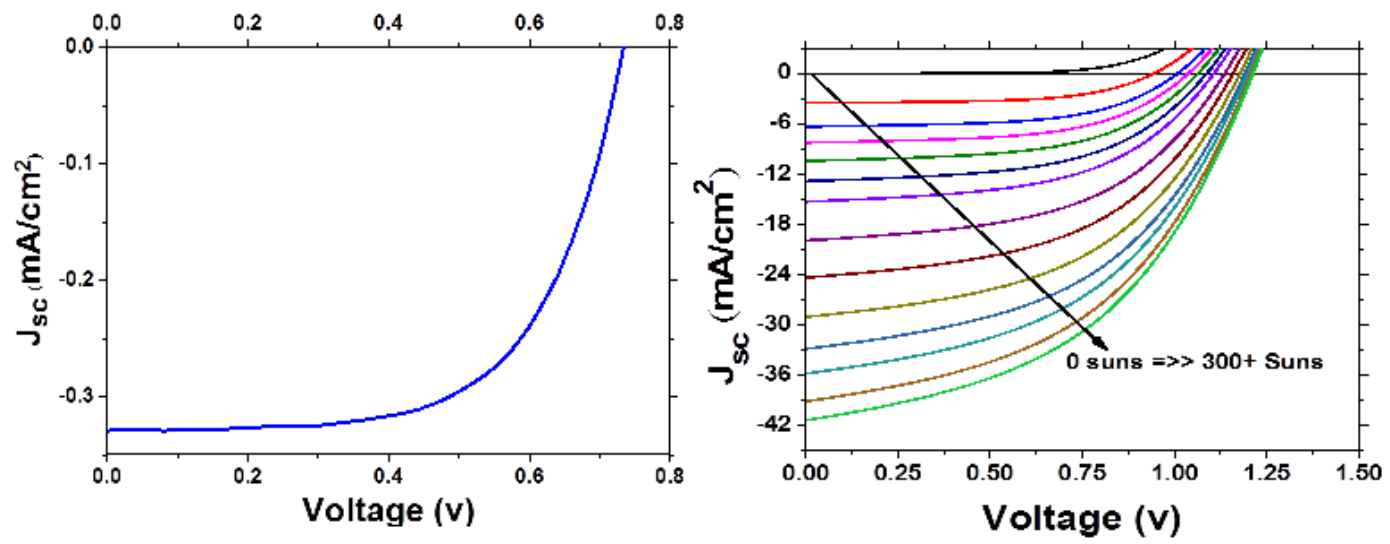

FIGURE 10. I-V under AM 1.5G (left), and under concentrated light (right)

The short circuit current density $\left(\mathrm{J}_{\mathrm{sc}}\right)$ is equal to $0.33 \mathrm{~mA} / \mathrm{cm}^{2}$, which is to our knowledge the maximum value reported so far for an InGaN/GaN PIN heterojunction with $8 \%$ of In incorporation. The open circuit voltage $\mathrm{V}_{\mathrm{oc}}$ is equal to $0.73 \mathrm{~V}$, which is a rather low value. To further investigate the device, we illuminated it under concentrated light as shown in Fig. 11. As expected, $\mathrm{J}_{\mathrm{sc}}$ increases linearly with the light-concentration and reaches a value of 42 $\mathrm{mA} / \mathrm{cm}^{2}$ under 300 suns, while the $\mathrm{V}_{\text {oc }}$ increases up to $1.22 \mathrm{~V}$, and saturates with further increase of the concentration. The detailed analysis of the factors responsible for the low $\mathrm{V}_{\text {oc }}$ are under way and will be published somewhere else. Nevertheless, we can assume that it is strongly related to the quality of the p-GaN layer as shown by Neufeld et al. [14] and ohmic contacts (a remaining Schottky barrier is probably existing [15]).

\section{- Nanorods approach based PIN structure}

We have realized a PIN heterojunction by growing $\mathrm{p}-\mathrm{GaN}$ at $1000^{\circ} \mathrm{C}$ for laterally covering InGaN nanopyramids grown on $\mathrm{n}-\mathrm{GaN}$ templates. The $\mathrm{p}-\mathrm{GaN}$ grown under hydrogen ambient and high temperature growth conditions entirely covers the thick InGaN nano-structures as shown in the inset of Fig. 11 a). The p-GaN has a hole concentration around $2 \times 10^{17} \mathrm{~cm}^{-3}$. The I-V measurements shown in Fig. $\left.11 \mathrm{a}\right)$ and $11 \mathrm{~b}$ ) are performed by putting the probes in direct contact with the material and no metallization was done. The I-V recorded in both planar and nanostructured areas reveal clear rectifying. These diodes have ideality factors around 4-5 comparable with others reported for InGaN core shell solar cells [16]. Almost three orders of magnitude larger current is obtained in the case of the nanostructure-based PIN. Furthermore, the ratio of the current measured at voltage of $+1 \mathrm{~V}$ and $-1 \mathrm{~V}$ is more than 20 times larger in the case of the nanostructure-based PIN. The area of the nano region is $10 \mathrm{um} \times 10 \mathrm{um}$, which makes it quite difficult for putting probes as well as metallization. New designs are in progress to achieve larger PIN structures for solar cell characterizations. Although the probe covers most of 10 um x 10 um pattern, we also recorded I-V under white illumination (Hg UV lamp). Results are shown in Fig. 11 b). Relatively large photocurrent is evidenced. These results evidence the higher overall quality of the nanostructure-based PIN.
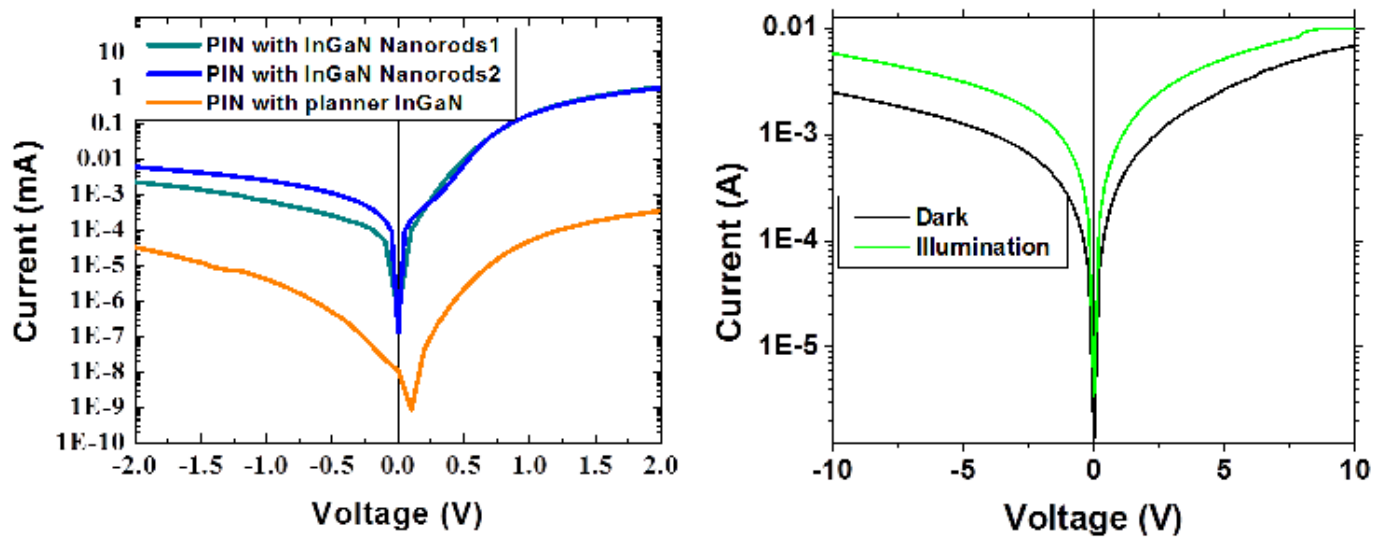

FIGURE 11. Dark and illuminated I-V characteristics of the PIN structure with embedded thick InGaN nanostructures on GaN templates in comparison with planar InGaN PIN structure. 


\section{CONCLUSION}

Several sets of InGaN layers (half PIN structures) with In content varying up to $30 \%$ have been grown using both approaches on GaN template substrates. The two approaches lead to structural, morphological, and luminescence properties that are significantly improved when compared to those of thick InGaN layers. Then the corresponding full PIN structures have been realized by growing a p-type GaN layer on the top the half PIN structures. External quantum efficiency and photo-current characterizations have been carried out on the different structures and reveal an enhancement of the performances of the InGaN PIN PV cells when the thick InGaN layer is replaced by either InGaN/GaN multi-layered or $\mathrm{InGaN}$ nanorod layer.

\section{ACKNOWLEDGEMENT}

This work was supported by the French National Research Agency (ANR), under the GANEX LABEX program and NOVAGAINS project (ANR-12-PRGE-0014-02), and CNRS INCEPT PEPS project.

\section{REFERENCES}

1. G. Bhuiyan, K. Sugita, A. Hashimoto, and A. Yamamoto, IEEE J. Photovoltaics 2, 276 (2012)

2. D. V. P. McLaughlin and J. M. Pearce, Metall. Mater. Trans. A 44, 1947 (2013)

3. O. Jani, B. Jampana, M. Mehta, H. Yu, I. Ferguson, R. Opila and C. Honsberg, IEEE (33rd PVSC) (2009)

4. J. K. Sheu, C.C. Yang, S.J. Tu, K.H. Chang, M.L. Lee, W.C. Lai, L.C. Peng, IEEE Electron. Device Lett. 30, 225 (2009).

5. N. G. Young, R. M. Farrell, Y. L. Hu, Y. Terao, M. Iza, S. Keller, S. P. DenBaars, S. Nakamura, and J. S. Speck, Appl. Phys. Lett.103, 173903 (2013).

6. L. Redaelli, A. Mukhtarova, S. Valdueza-Felip, A. Ajay, C. Bougerol, C. Himwas, J. Faure-Vincent, C. Durand, J. Eymery, and E. Monroy Appl. Phys.Lett. 105, 131105 (2014)

7. W. H. Goh, G. Patriarche, P. L. Bonanno, S. Gautier, T. Moudakir, M. Abid, G. Orsal, A. A. Sirenko, Z. Cai, A. Martinez, A. Ramdane, L. Le Gratiet, A. Soltani, and A. Ougazzaden, J. Cryst. Growth 315, 160 (2011)

8. S. Sundaram, R. Puybaret, Y. El Gmili, X. Li, P. L.Bonanno, K. Pantzas, G. Orsal, D. Troadec, Z.-H. Cai, G. Patriarche, P. L. Voss, J. P. Salvestrini, and A. Ougazzaden, J. Appl. Phys. 116, 163105 (2014)

9. S. Gautier, C. Sartel, S. Ould-Saad, J. Martin, A. Sirenko, and A.Ougazzaden, J.Cryst Growth 298,428 (2007)

10. K. Pantzas, G. Patriarche, G. Orsal, S. Gautier, T. Moudakir, M. Abid, V. Gorge, Z. Djebbour, P. L. Voss, and A. Ougazzadenet al. Phys Status Solidi A 209, 25 (2012).

11. Y. El Gmili, G. Orsal, K. Pantzas, T. Moudakir, S. Sundaram, G.Patriarche, A. Ahaitouf, J. P. Salvestrini, and A. Ougazzaden, Acta Mater. 61(17), 6587 (2013).

12. Y. El Gmili, G. Orsal, K. Pantzas, A. Ahaitouf, T. Moudakir, S. Gautier,G. Patriarche, D. Troadec, J. P. Salvestrini, and A. Ougazzaden, Opt.Mater. Express 3(8), 1111 (2013).

13. J. R. Lang, C. J. Neufeld, C. A. Hurni, S. C. Cruz, E. Matioli, U. K. Mishra and J. S. Speck, Appl. Phys. Lett. 98 (13), 131115-131115 (2011).

14. C. J. Neufeld, Z. Chen, S. C. Cruz, N. G. Toledo, S. P. DenBaars and U. K. Mishra, IEEE (35th PVSC), 002090-002092 (2010)

15. O. Jani, C. Honsberg, Y. Huang, J.-O. Song, I. Ferguson, G. Namkoong, E. Trybus, A. Doolittle and S. Kurtz, IEEE Vol. 1, 20-25 (2006).

16. Y. Dong, B. Tian, T. J. Kempa, and C. M. Lieber, Nano Lett. 9, 2183 (2009). 